\title{
Membrane Technologies for Lactic Acid Separation from Fermentation Broths Derived from Renewable Resources
}

\author{
Maria Alexandri, Roland Schneider and Joachim Venus * (D) \\ Leibniz Institute for Agricultural Engineering and Bioeconomy (ATB), Max-Eyth-Allee 100, 14469 Potsdam, \\ Germany; malexandri@atb-potsdam.de (M.A.); rschneider@atb-potsdam.de (R.S.) \\ * Correspondence: jvenus@atb-potsdam.de; Tel.: +49-0-331-5699-852
}

Received: 4 September 2018; Accepted: 5 October 2018; Published: 12 October 2018

\begin{abstract}
Lactic acid (LA) was produced on a pilot scale using a defined medium with glucose, acid whey, sugar bread and crust bread. The fermentation broths were then subjected to microand nanofiltration. Microfiltration efficiently separated the microbial cells. The highest average permeate flow flux was achieved for the defined medium $\left(263.3 \mathrm{~L} / \mathrm{m}^{2} / \mathrm{h}\right)$ and the lowest for the crust bread-based medium $\left(103.8 \mathrm{~L} / \mathrm{m}^{2} / \mathrm{h}\right)$. No LA losses were observed during microfiltration of the acid whey, whilst the highest retention of LA was $21.5 \%$ for crust bread. Nanofiltration led to high rejections of residual sugars, proteins and ions (sulphate, magnesium, calcium), with a low retention of LA. Unconverted sugar rejections were $100 \%$ and $63 \%$ for crust bread and sugar bread media respectively, with corresponding LA losses of $22.4 \%$ and $2.5 \%$. The membrane retained more than $50 \%$ of the ions and proteins present in all media and more than $60 \%$ of phosphorus. The average flux was highly affected by the nature of the medium as well as by the final concentration of LA and sugars. The results of this study indicate that micro- and nanofiltration could be industrially employed as primary separation steps for the biotechnologically produced LA.
\end{abstract}

Keywords: lactic acid; microfiltration; nanofiltration; electrodialysis; purification

\section{Introduction}

Bio-based production of platform chemicals from renewable resources is currently a topic of intensive research. Lactic acid is an important bulk chemical with a global market of $1220.0 \mathrm{kt}$ in 2016 [1]. The lactic acid market presents an annual growth of $16.2 \%$, mainly due to the production of polylactic acid and ethyl lactate, whilst the estimated demand for 2025 is $1960.1 \mathrm{kt}$ [1,2]. Lactic acid can be produced biotechnologically from various renewable resources and waste streams such as food waste [3-5], mixed bakery waste [6], coffee pulp and mucilage [7,8], algal biomass [9], and lignocellulosic hydrolysates [10] among others.

The utilization of waste and by-product streams as alternative fermentation substrates could reduce the cost of the upstream process of bulk chemicals and, at the same time, their production would not compete with food and feed. On the other hand, renewable materials like lignocellulosic biomass result in an undefined medium, rendering the downstream process of organic acids more complicated. For lactic acid, the cost for its separation and purification from the fermentation broth can reach $50 \%$ of the total process costs [1]. Calcium precipitation was the most common method for organic acid separation but large quantities of gypsum are generated and the resultant lactic acid presents low purity [1]. Various separation methods have been proposed in the literature so far, including solvent extraction, membrane separation, ion exchange chromatography, and reactive distillation aiming to overcome these drawbacks [1]. 
Membrane separation techniques have recently attracted attention as they are environmentally benign and easily scaled up [11]. Microfiltration (MF) is an effective method for the removal of microbial biomass, while nanofiltration (NF) efficiently retains proteins and other macromolecules as well as multivalent anions [11,12]. Many researchers have already demonstrated lactic acid separation using NF techniques either from fermentation broths or from defined solutions [13].

The aim of this study is to demonstrate the efficient separation of lactic acid from different fermentation broths. In all cases, lactic acid fermentation was carried out on a pilot scale using three inexpensive substrates (crust bread, sugar bread, and acid whey) or a defined glucose solution. MF and NF were applied in all cases aiming to separate lactic acid from other fermentation components.

\section{Materials and Methods}

\subsection{Microorganisms}

Different Bacillus coagulans strains were used for the fermentation of each medium according to the special substrate requirements. Strain A20 was isolated from potato washing water and tested for the fermentation of the defined medium. Strains A369 and A107 were isolated from rapeseed meal and were utilized for the fermentation of acid whey and sugar bread respectively. Finally, fermentation of crust bread was carried out by the strain A59, isolated from rye grain. An inoculum preparation was carried out in De Man, Rogosa and Sharpe (MRS) broth (Merck, Darmstadt, Germany) and $0.67 \mathrm{~g}$ Everzit Dol (Evers e.K., Hopsten, Germany) dolomite as a buffer. The strains were cultivated at $52{ }^{\circ} \mathrm{C}$ for $10-16 \mathrm{~h}$, at $100 \mathrm{rpm}$ on an orbital shaker.

\subsection{Substrate Preparation}

Sugar bread and crust bread were kindly provided by CETECE (Palencia, Spain). Starch hydrolysis was carried out using the commercial enzymatic preparations BAN 240L (Novozymes, Bagsvaerd, Denmark), Stargen 002 (Genencor, New York, NY, USA), Viscoferm (Novozymes, Bagsvaerd, Denmark), whilst Protease N-01 (ASA-Spezialenzyme GmbH, Wolfenbüttel, Germany) was added for protein hydrolysis. Acid whey was supplied by Glanbia Ingredients (Kilkenny, Ireland) and was readily utilized for fermentation.

\subsection{Pilot Scale Fermentations}

A pilot scale bioreactor with 1000 L capacity (A\&B Heldrungen GmbH, Heldrungen, Germany) was employed for all of the fermentations, with different working volumes depending on the media applied. All fermentations were carried out in batch mode, at $52{ }^{\circ} \mathrm{C}$, and the $\mathrm{pH}$ was adjusted to 6.0 using $20 \% \mathrm{NaOH}(w / w)$. At the end of the fermentation, the medium was heated up to $85^{\circ} \mathrm{C}$ for $1.5 \mathrm{~h}$ in order to deactivate the biomass. Inactivation was carried out using steam directly in the medium, resulting in an increase in the final volume.

Batch fermentations were carried out using four different substrates: a defined medium, acid whey, a sugar bread hydrolysate and a crust bread hydrolysate. For the preparation of the defined medium, $120 \mathrm{~g} / \mathrm{L}$ of glucose was utilized as a carbon source with $15 \mathrm{~g} / \mathrm{L}$ of yeast extract. The working volume of the fermentation was $700 \mathrm{~L}$. Fermentation with acid whey was carried out using a $300 \mathrm{~L}$ working volume, in the presence of $10 \mathrm{~g} / \mathrm{L}$ yeast extract. Sugar bread and crust bread hydrolysates were utilized as carbon and nutrient sources supplemented with $10 \mathrm{~g} / \mathrm{L}$ and $5 \mathrm{~g} / \mathrm{L}$ yeast extract, respectively. The working volume for both fermentations was $600 \mathrm{~L}$. Inocula for all fermentations were $6 \%$ and the preparation was carried out under the same culture conditions in a 72 L BIOSTAT UD bioreactor (B-Braun Biotech, Melsungen, Germany). Samples were taken at regular intervals for the analysis of sugars and lactic acid. Inactivation of the samples was carried out in a water bath at $95{ }^{\circ} \mathrm{C}$ for $20 \mathrm{~min}$. 


\subsection{Membranes and Experimental Procedures}

A schematic diagram describing the overall studied process is presented in Figure 1. After the inactivation of the biomass, the medium was filtrated using a UFI-TEC cross-flow microfiltration system (UFI-TEC GmbH, Oranienburg, Germany), operating at 1.5 bar and equipped with 4 ceramic membranes CéRAM INSIDE (TAMI Industries, Nyons, France), $\mathrm{ZrO}_{2}-\mathrm{TiO}_{2}$, with a pore size of $0.2 \mu \mathrm{m}$ and a $6.65 \mathrm{~m}^{2}$ surface area. Losses of the medium during microfiltration were monitored (Table 1) due to some stops during the process.

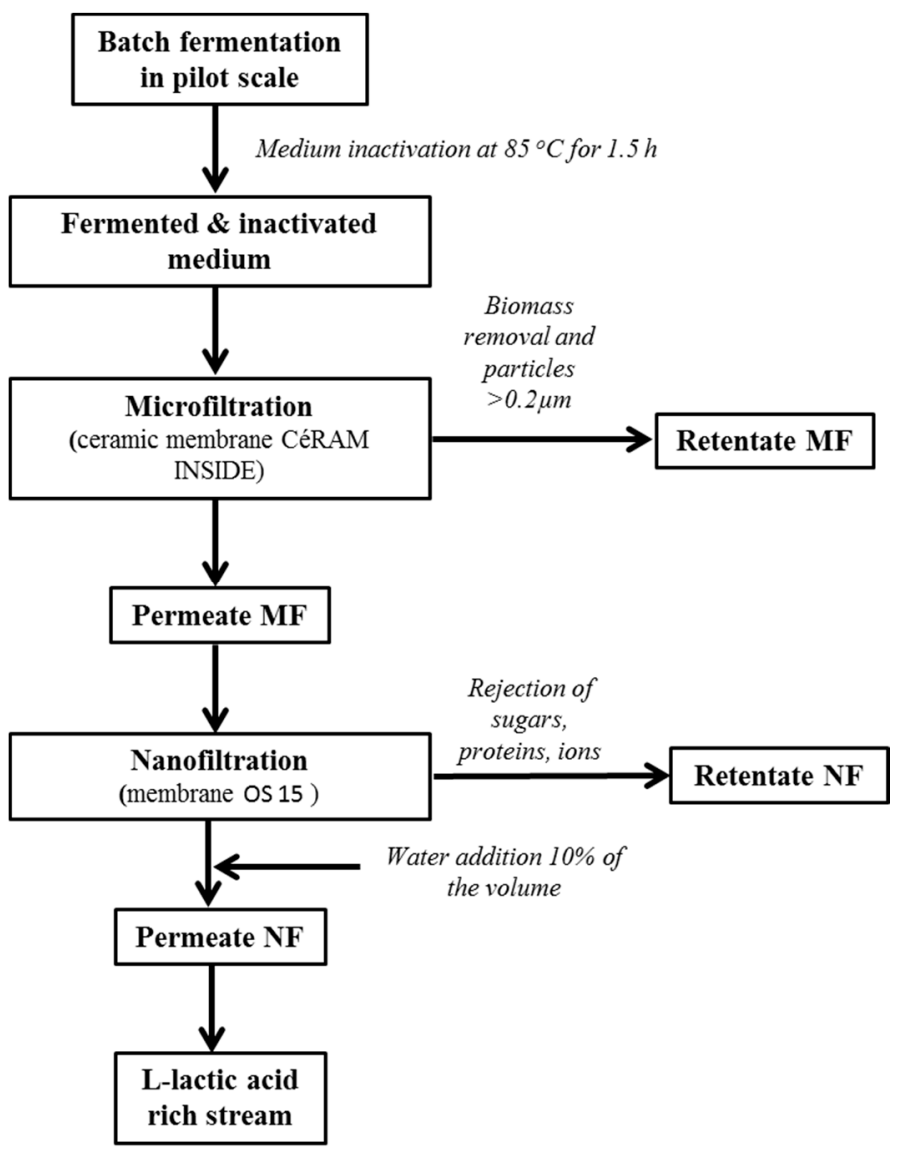

Figure 1. Schematic diagram of the studied process.

Table 1. Material balances (L) of the different substrates after each treatment.

\begin{tabular}{cccccccccc}
\hline & \multicolumn{4}{c}{ Microfiltration } & \multicolumn{3}{c}{ Nanofiltration } \\
\hline Substrate & $\begin{array}{c}\text { End of } \\
\text { Fermentation }\end{array}$ & $\begin{array}{c}\text { After } \\
\text { Inactivation }\end{array}$ & Permeate & Retentate & Losses & $\begin{array}{c}\text { Volume } \\
\text { Processed }\end{array}$ & Permeate Retentate & $\begin{array}{c}\text { Water } \\
\text { Addition }\end{array}$ \\
\hline $\begin{array}{c}\text { defined } \\
\text { medium }\end{array}$ & 878 & 941 & 910 & 31 & 0 & 103.5 & 105 & 8.1 & 10 \\
acid whey & 320 & 349 & 327 & 22 & 0 & 296.8 & 293.5 & 33 & 30 \\
sugar bread & 735 & 788 & 705 & 67 & 16 & 705 & 718.6 & 53 \\
crust bread & 730 & 784 & 640 & 119 & 25 & 640 & 637.5 & 60.9 & 60 \\
\hline
\end{tabular}

The permeate stream obtained from the microfiltration was subjected to nanofiltration at 30 bar and at $30{ }^{\circ} \mathrm{C}$ using a UFI-TEC cross-flow nanofiltration system (UFI-TEC, GmbH, Oranienburg, Germany). The membrane utilized was OS 15 (DOW Chemical Company, Schwalbach, Germany) with a cut-off of 150-300 Da. According to the manufacturer, the membrane area was $1.7 \mathrm{~m}^{2}$ and the average permeate flow was $1.7 \mathrm{~m}^{3} /$ day. This membrane presented a $96 \%$ salt rejection (using $\mathrm{MgSO}_{4}$ ), with a maximum working pressure of $4.14 \mathrm{MPa}$ (when operating at temperatures $<35^{\circ} \mathrm{C}$ ) and a $50{ }^{\circ} \mathrm{C}$ maximum working temperature. Water flux analysis was monitored at 6, 10 and 20 bar. The MF 
permeate was divided into batches of approximately $100 \mathrm{~mL}$ and then introduced to the nanofiltration membranes. The treated volumes are presented in Table 1. For every substrate, water was added close to the end of the filtration, aiming to reduce the viscosity of the retentate and decrease the loss of lactic acid. The amount of the water added was approximately $10 \%$ of the initial volume (Table 1).

\subsection{Calculations}

The permeate flux (J) for MF and NF was calculated using the following equation:

$$
\mathrm{J}=\mathrm{Q}_{\mathrm{p}} / \mathrm{Am}
$$

where $Q_{p}$ is the filtrate flow rate through the membrane and Am is the surface area of the membrane. The permeate flux is expressed in $\mathrm{L} / \mathrm{h} / \mathrm{m}^{2}$.

The rejection percentage for a specified compound (sugars, lactic acid, proteins, ions) was calculated as follows:

$$
\mathrm{R}=1-\mathrm{C}_{\mathrm{p}} / \mathrm{C}
$$

where $C_{p}$ is the concentration of the specified compound in the permeate stream and $C$ is the corresponding concentration in the feed.

\subsection{Analytical Methods}

The concentration of lactic acid and sugars was analyzed by HPLC (DIONEX, Sunnyvale, CA, USA), using a Eurokat H column (300 mm $\times 8 \mathrm{~mm} \times 10 \mu \mathrm{m}$, Knauer, Berlin, Germany), with $5 \mathrm{mM}$ $\mathrm{H}_{2} \mathrm{SO}_{4}$ as the mobile phase at a flow rate of $0.8 \mathrm{~mL} / \mathrm{min}$. The injection volume was $10 \mu \mathrm{L}$ and detection was carried out using a refractive index detector (RI-71. Shodex/Shoko Science Co., Tokyo, Japan). The analysis of cations and anions was carried out by ion chromatography (DIONEX, Sunnyvale, CA, USA). Cation determination was achieved using an IonPac CS 16 column $(250 \mathrm{~mm} \times 4 \mu \mathrm{m}$, DIONEX, Sunnyvale, CA, USA), using $30 \mathrm{mM} \mathrm{CH}_{3} \mathrm{SO}_{3} \mathrm{H}$ at a flow rate of $1.0 \mathrm{~mL} / \mathrm{min}$, at $40{ }^{\circ} \mathrm{C}$. Determination of anions was carried out with an IonPac AS9-HC column $(250 \mathrm{~mm} \times 4 \mu \mathrm{m}$, DIONEX, Sunnyvale, CA, USA), using $9 \mathrm{mM} \mathrm{Na}_{2} \mathrm{CO}_{3}$ as the mobile phase, at a flow rate of $1.2 \mathrm{~mL} / \mathrm{min}$, operating at room temperature.

The protein content of the samples was expressed as Kjeldahl-nitrogen and determination was carried out according to the DIN-EN-25663 standard method.

The total phosphorus $(\mathrm{P})$ content was measured by flow injection analysis (FIA), according to the international standard ISO 15681-1, 2003.

\section{Results and Discussion}

\subsection{Fermentation}

The replacement of commercial sugars and nutrients with waste and by-product streams could not only decrease the upstream cost of the biotechnological production of lactic acid but it would also contribute to the sustainable production of platform chemicals in general. Figure 2 presents the kinetics of four individual batch fermentations in pilot scale, using (A) a defined medium with glucose, (B) acid whey, (C) sugar bread, and (D) crust bread. When a defined medium with glucose as the single carbon source was utilized, fermentation lasted for $48 \mathrm{~h}$, resulting in $99.5 \mathrm{~g} / \mathrm{L}$ of lactic acid with the strain A20 (Figure 2A). The lactic acid yield from the total glucose concentration was $0.87 \mathrm{~g} / \mathrm{g}$ and the productivity was $2.11 \mathrm{~g} / \mathrm{L} / \mathrm{h}$. For the fermentation using acid whey as a substrate, isolate A369 was selected since it has the ability to consume lactose. This medium also contained $7.3 \mathrm{~g} / \mathrm{L}$ of lactic acid. Lactose consumption started during the first $2 \mathrm{~h}$ of fermentation but with a lower rate in comparison to glucose (Figure 2B). Some galactose was also detected in the broth during the process. After $71 \mathrm{~h}$ of fermentation, $28.8 \mathrm{~g} / \mathrm{L}$ of lactic acid was produced with a yield and productivity of $0.60 \mathrm{~g} / \mathrm{g}$ (on total sugars) and $0.51 \mathrm{~g} / \mathrm{L} / \mathrm{h}$, respectively. No other by-products were detected in the medium. 

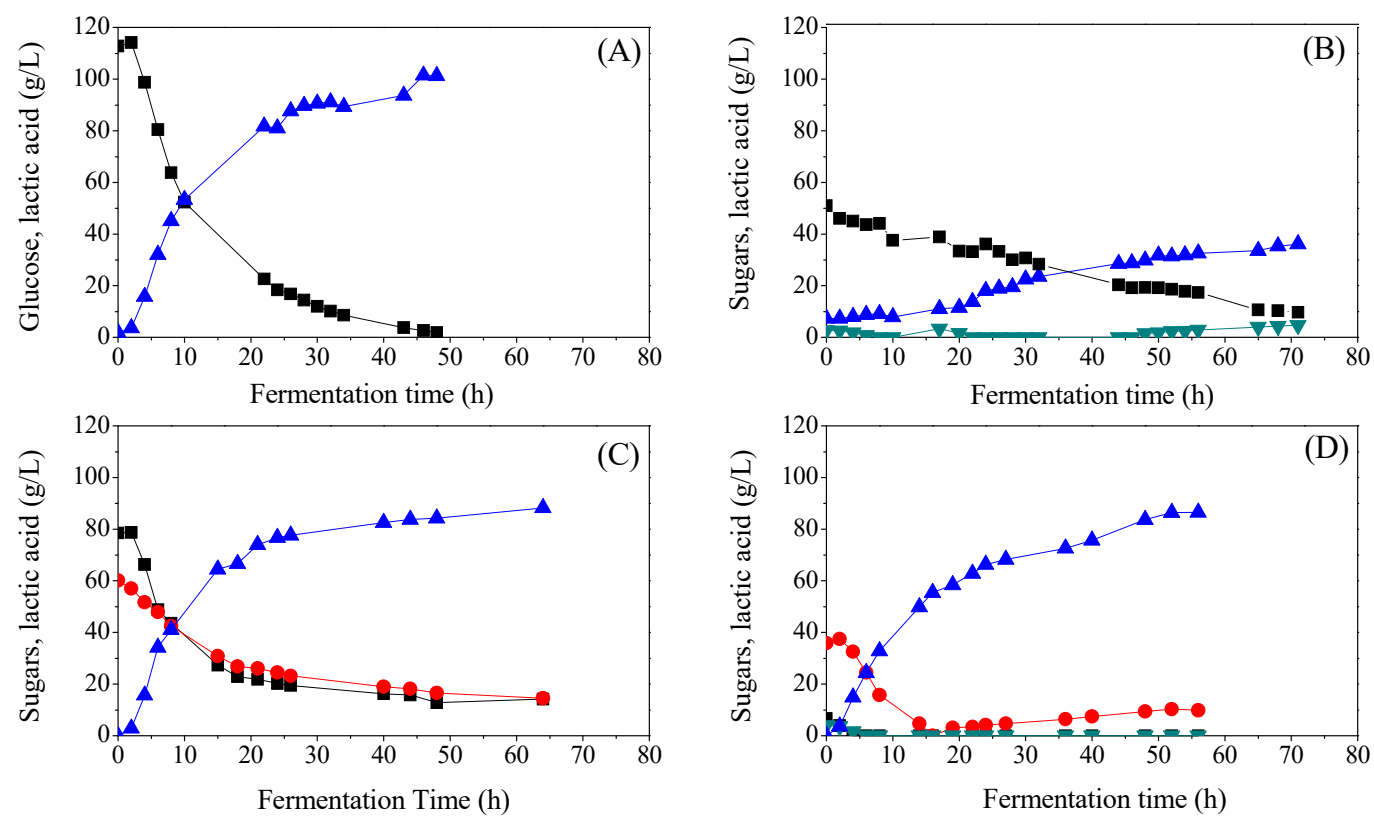

Figure 2. Sugar consumption and lactic acid production during fermentation of (A) defined medium; (B) acid whey; (C) sugar bread and (D) crust bread. Glucose and lactose (black square), galactose and fructose (dark cyan down-pointing triangle), sucrose and maltose (red cycle), lactic acid (blue up-pointing triangle).

Sugar bread and crust bread are two starch-rich substrates. Strain A107 was selected for the fermentation using sugar bread and strain A59 for the case of crust bread. After hydrolysis, the sugar bread contained $78.5 \mathrm{~g} / \mathrm{L}$ of glucose and $60.1 \mathrm{~g} / \mathrm{L}$ of disaccharides, which is probably a mixture of sucrose and maltose but due to analytic restrictions, it was not possible to separate them. Sugar consumption with parallel lactic acid production started in the first $2 \mathrm{~h}$ of fermentation, with a clear preference for glucose. Within $48 \mathrm{~h}, 84.3 \mathrm{~g} / \mathrm{L}$ of lactic acid was produced, with a yield of $0.70 \mathrm{~g} / \mathrm{g}$ and $1.76 \mathrm{~g} / \mathrm{L} / \mathrm{h}$ productivity (Figure $2 \mathrm{C}$ ). The process was stopped after $64 \mathrm{~h}$ since sugar consumption almost ceased.

Strain A59 was selected for the fermentation of crust bread due to its ability to produce its own amylases. The initial sugar concentration was $46.5 \mathrm{~g} / \mathrm{L}$, of which, $6.7 \mathrm{~g} / \mathrm{L}$ was glucose, $3.9 \mathrm{~g} / \mathrm{L}$ fructose and $35.9 \mathrm{~g} / \mathrm{L}$ disaccharide (most possibly maltose) (Figure 2D). All sugars were consumed within $16 \mathrm{~h}$ with the production of $55.4 \mathrm{~g} / \mathrm{L}$ of lactic acid. Glucose was not detected again in the medium but the presence of the disaccharide indicated that the strain was able to hydrolyze the residual starch. The process was stopped after $65 \mathrm{~h}$ since lactic acid production stabilized at $86.4 \mathrm{~g} / \mathrm{L}$. Productivity (at $52 \mathrm{~h}$ ) was $1.66 \mathrm{~g} / \mathrm{L} / \mathrm{h}$. Due to the hydrolyzing ability of the strain, it was not possible to calculate the yield of lactic acid from the sugar content.

The fermentation results on the pilot scale demonstrate that lactic acid can be biotechnologically produced from different raw materials. The defined medium resulted in the highest values of final lactic acid concentration $(99.5 \mathrm{~g} / \mathrm{L})$, yield $(0.87 \mathrm{~g} / \mathrm{g})$ and productivity $(2.11 \mathrm{~g} / \mathrm{L} / \mathrm{h})$ but the starch based media (crust and sugar bread) were also suitable substrates. There are not many studies in the literature dealing with the production of lactic acid in pilot scales. Karp [14] studied the fermentation of vinasse enriched with soybean molasses for lactic acid production using the strain Lactobacillus agilis LPB 56, in an $80 \mathrm{~L}$ pilot scale bioreactor. The yield and productivity presented were $0.849 \mathrm{~g} / \mathrm{g}$ and $0.863 \mathrm{~g} / \mathrm{L} / \mathrm{h}$, respectively. Coupling the fermentation with a ceramic membrane system for in situ product separation led to an increased lactic acid production both in terms of final concentration and productivity. In the study of $\mathrm{Lu}$ [15], the authors reported L(+)-lactic acid concentration of $157.22 \mathrm{~g} / \mathrm{L}$ and a volumetric productivity of $8.77 \mathrm{~g} / \mathrm{L} / \mathrm{h}$. Pleissner [7] tested the strain B. coagulans for the fermentation of coffee 
pulp on pilot scales, achieving a yield of $0.78 \mathrm{~g} / \mathrm{g}$ and a productivity of $4.02 \mathrm{~g} / \mathrm{L} / \mathrm{h}$. It is obvious that substrate, strain selection, and fermentation mode can highly affect the upstream process.

After the efficient production of lactic acid, its separation and purification from the fermentation broth are equally crucial for polymer grade lactic acid. At the same time, the downstream process should be equally sustainable and environmentally benign. To this end, membrane filtration was applied in all substrates, aiming to separate lactic acid from the other fermentation components.

\subsection{Microfiltration}

Microfiltration is an efficient method for the removal of cell biomass, without major lactic acid losses. The composition of the initial stream (after inactivation), that was fed to the microfiltration, is presented in Table 2.

Table 2. Composition of the fermentation broths after medium inactivation.

\begin{tabular}{ccccccc}
\hline Substrate & $\begin{array}{c}\text { Glucose } \\
(\mathrm{g} / \mathrm{L})\end{array}$ & $\begin{array}{c}\text { Disaccharide } \\
(\mathrm{g} / \mathrm{L})\end{array}$ & $\begin{array}{c}\text { Fru/Xyl/Gal } \\
(\mathrm{g} / \mathrm{L})\end{array}$ & $\begin{array}{c}\text { Lactic Acid } \\
(\mathrm{g} / \mathrm{L})\end{array}$ & $\begin{array}{c}\text { Monovalent } \\
\text { Ions }(\mathbf{m g} / \mathrm{L})\end{array}$ & $\begin{array}{c}\text { Divalent } \\
\text { Ions }(\mathbf{m g} / \mathrm{L})\end{array}$ \\
\hline Defined & 1.26 & n.d. & n.d. & 90.4 & $27,083.6$ & 201.0 \\
medium & & 8.9 & 4.2 & 33.0 & $36,657.0$ & 1839.0 \\
Acid whey & n.d. & 13.0 & n.d. & 77.0 & $21,207.4$ & 264.4 \\
Sugar Bread & 10.0 & 10.0 & n.d. & 76.0 & $20,151.0$ & 402.0 \\
Crust Bread & n.d. & &
\end{tabular}

Table 3 presents the initial volume of every stream, the time required for the microfiltration, the volume reduction $(\mathrm{VR})$, the average permeate flux $\left(\mathrm{Javer}_{\mathrm{av}}\right)$ as well as the percentage of sugar rejection and lactic acid losses. Fermentation broths derived from crust bread and sugar bread had almost the same final volume and very similar nature since there were both starch-rich substrates. However, microfiltration of the crust bread fermentation broth required much more time in comparison to sugar bread. Moreover, the average permeate flux was approximately $62.3 \%$ higher in the sugar bread than in the crust bread. Microfiltration of acid whey was the fastest but the overall volume of the broth was less. As expected, the defined medium was the easiest substrate to microfilter, since, for the initial volume used, the process was faster and presented the highest average permeate flux $\left(263.3 \mathrm{~L} / \mathrm{m}^{2} / \mathrm{h}\right)$.

Table 3. Initial volume $\left(\mathrm{V}_{\text {in }}\right)$, microfiltration time, average permeate flux ( $\left.\mathrm{J}_{\text {aver }}\right)$, volume reduction (VR), sugar rejection and lactic acid losses during microfiltration of the different substrates.

\begin{tabular}{|c|c|c|c|c|c|c|}
\hline Substrate & $\mathrm{V}_{\text {in }}(\mathrm{L})$ & Time (min) & VR (\%) & $\mathrm{J}_{\text {aver }}\left(\mathrm{L} / \mathrm{m}^{2} / \mathrm{h}\right)$ & $\begin{array}{c}\text { Sugar Rejection } \\
(\%)\end{array}$ & $\begin{array}{l}\text { Lactic Acid } \\
\text { Losses (\%)* }\end{array}$ \\
\hline $\begin{array}{l}\text { Defined } \\
\text { medium }\end{array}$ & 941 & 34 & 3.3 & 263.3 & 1.6 & 3.2 \\
\hline Acid whey & 349 & 23 & 11.2 & 143.7 & 0 & 0 \\
\hline $\begin{array}{l}\text { Sugar } \\
\text { bread }\end{array}$ & 788 & 39 & 10.5 & 166.4 & 15.4 & 17.5 \\
\hline $\begin{array}{l}\text { Crust } \\
\text { bread }\end{array}$ & 784 & 83 & 18.4 & 103.8 & 21.6 & 21.5 \\
\hline
\end{tabular}

Among the alternative substrates, the highest losses of lactic acid (21.5\%) were observed from the crust bread hydrolysate, whereas from sugar bread the losses were slightly lower (17.5\%) (Table 3). No sugar or lactic acid losses were detected when acid whey was microfiltered, whilst from the defined glucose solution, lactic acid losses were only 3.2\% (Table 3). Residual sugars were also partially rejected after this processing step and their retention had the same profile as lactic acid; $21.6 \%$ from crust bread, followed by $15.4 \%$ from sugar bread and $1.6 \%$ from the defined glucose solution (Table 3). 
In Figure 3, the evolution of permeate flux is demonstrated. The reduction of the permeate flux is evident for all the studied media. The highest stability was observed when the defined solution was used (Figure 3A). Microfiltration started with a permeate flux of $386.5 \mathrm{~L} / \mathrm{h} / \mathrm{m}^{2}$, which remained approximately at $300 \mathrm{~L} / \mathrm{h} / \mathrm{m}^{2}$ during the process. After about $42 \mathrm{~min}$ of filtration, the permeate flux decreased to $150 \mathrm{~L} / \mathrm{h} / \mathrm{m}^{2}$, to end up at $36 \mathrm{~L} / \mathrm{h} / \mathrm{m}^{2}$, due to a pump failure. For the case of acid whey, the permeate flux rate fell abruptly during the first minutes of filtration (from $350.4 \mathrm{~L} / \mathrm{h} / \mathrm{m}^{2}$ to $108.3 \mathrm{~L} / \mathrm{h} / \mathrm{m}^{2}$ after $10 \mathrm{~min}$ ) but then it remained almost stable (around $117 \mathrm{~L} / \mathrm{h} / \mathrm{m}^{2}$ ) until the end of the process (Figure 3B). A reduction of the permeate flux during the first $10 \mathrm{~min}$ of microfiltration also occurred during the processing of the sugar bread fermentation broth (from $225.6 \mathrm{~L} / \mathrm{h} / \mathrm{m}^{2}$ to $136.8 \mathrm{~L} / \mathrm{h} / \mathrm{m}^{2}$ ) (Figure 3C). The drop of permeate flux during microfiltration could be attributed to the concentration polarization and the formation of a cake layer from the microbial cells $[16,17]$. Interestingly, the flux slightly increased over the process (highest value of $194 \mathrm{~L} / \mathrm{h} / \mathrm{m}^{2}$ after $48 \mathrm{~min}$ ) and decreased again at the end of the filtration $\left(108.3 \mathrm{~L} / \mathrm{h} / \mathrm{m}^{2}\right)$. This increment of the flux could be associated with the rise of the substrate's temperature. Microfiltration of crust bread started with a constant reduction of the permeate flux until it stabilized at the lowest value of about $40 \mathrm{~L} / \mathrm{h} / \mathrm{m}^{2}$ in comparison to all the other substrates (Figure 3D). At the end of the filtration, the permeate flux was only $15 \mathrm{~L} / \mathrm{h} / \mathrm{m}^{2}$. It is, therefore, quite evident that the nature of the substrate can significantly alter the filtration efficiency and time.
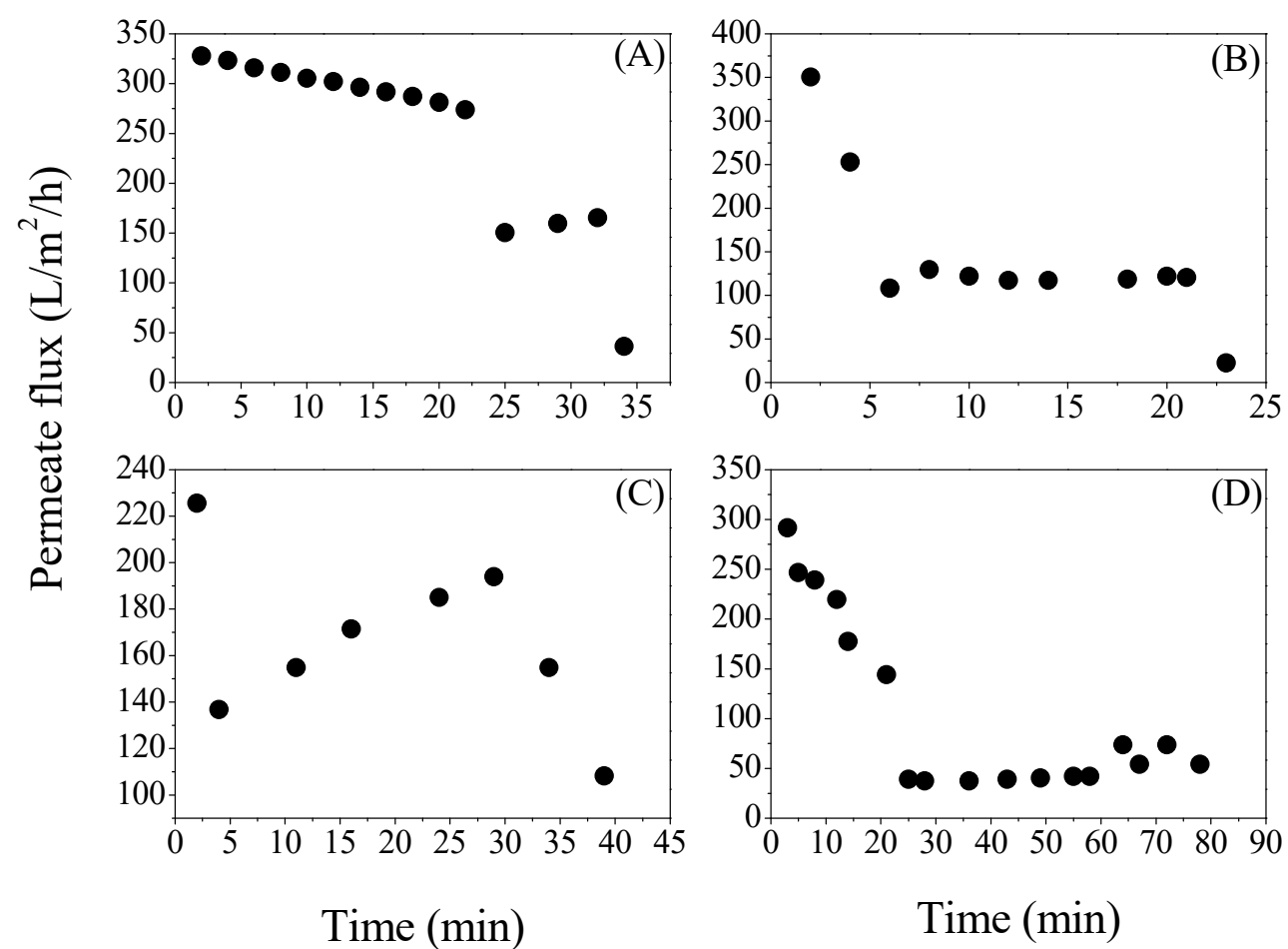

Figure 3. Evolution of the permeate flux (J) during microfiltration of (A) defined medium; (B) acid whey; (C) sugar bread and (D) crust bread.

\subsection{Nanofiltration}

\subsubsection{Permeate Flux of the Different Substrates}

Nanofiltration was equally affected by the type of substrate employed as in the case of the microfiltration. The Javer was higher for the defined glucose solution $\left(95.9 \mathrm{~L} / \mathrm{h} / \mathrm{m}^{2}\right)$, followed by the crust bread $\left(31.6 \mathrm{~L} / \mathrm{h} / \mathrm{m}^{2}\right)$, acid whey $\left(18.5 \mathrm{~L} / \mathrm{h} / \mathrm{m}^{2}\right)$ and the lowest one was found for the sugar bread substrate $\left(12.4 \mathrm{~L} / \mathrm{h} / \mathrm{m}^{2}\right)$. The profile of the permeate flux during filtration time was also quite different and highly dependent on the substrate (Figure 4). 

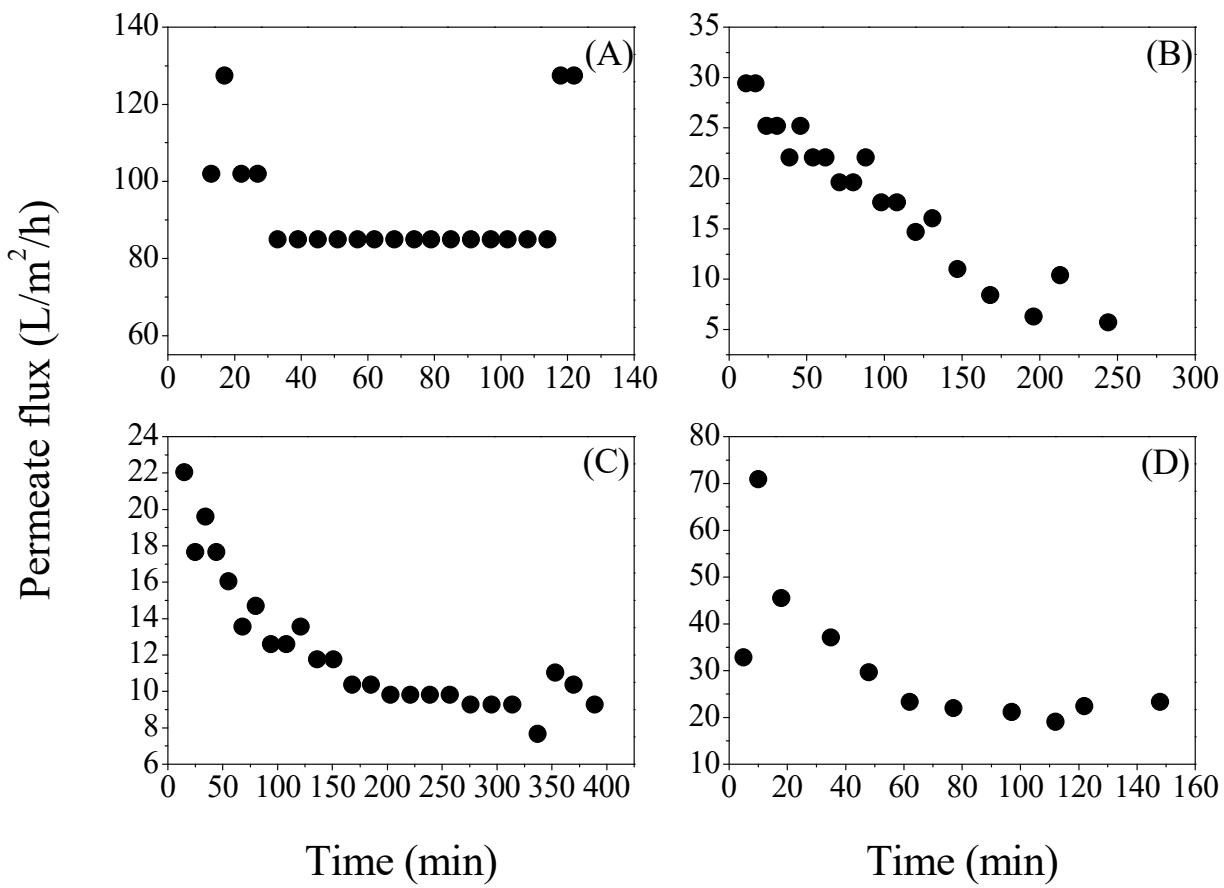

Figure 4. Evolution of the permeate flux (J) during nanofiltration of (A) defined medium; (B) acid whey; (C) sugar bread and (D) crust bread.

The permeate flux during the nanofiltration of the defined glucose medium was quite stable and it remained - as in case of microfiltration - for almost the entire process at a value of about $85 \mathrm{~L} / \mathrm{h} / \mathrm{m}^{2}$ (Figure 4A). The addition of $10 \mathrm{~L}$ of water close to the end of the filtration resulted in an increase of the permeate flux to its initial values $\left(127.5 \mathrm{~L} / \mathrm{h} / \mathrm{m}^{2}\right)$. Nanofiltration of $103.5 \mathrm{~L}$ lasted for $122 \mathrm{~min}$. For sugar bread, a decrease of the permeate flux was observed throughout the filtration (Figure 4C). Initially, the permeate flux was at $22.1 \mathrm{~L} / \mathrm{h} / \mathrm{m}^{2}$ and it slowly decreased to $10 \mathrm{~L} / \mathrm{h} / \mathrm{m}^{2}$ and stabilized until the end of the process.

When the crust bread hydrolysate was nanofiltered, during the first $5 \mathrm{~min}$, the permeate flux was only $32 \mathrm{~L} / \mathrm{h} / \mathrm{m}^{2}$ but then increased to $70 \mathrm{~L} / \mathrm{h} / \mathrm{m}^{2}$ and stabilized at approximately $20 \mathrm{~L} / \mathrm{h} / \mathrm{m}^{2}$. For a volume of $111 \mathrm{~L}, 148 \mathrm{~min}$ of nanofiltration was required (Figure 4D). The acid whey nanofiltration followed a similar trend to the sugar bread since the decrease of permeate flux was evident (Figure 4B). The initial permeate flux was $29.4 \mathrm{~L} / \mathrm{h} / \mathrm{m}^{2}$ and at the end of the process, it presented a value of $5.7 \mathrm{~L} / \mathrm{h} / \mathrm{m}^{2}(244 \mathrm{~min})$. The decline of the permeate flux in all cases was a very common phenomenon in nanofiltration and it is reported to be also correlated with the high lactic acid concentrations [17].

The permeate fluxes during both MF and NF were higher for the defined medium; a result that can be easily attributed to the viscosity and complexity of the waste streams used for fermentation [18]. The highest Javer during NF was achieved using the defined medium or crust bread, with values of 95.9 and $31.6 \mathrm{~L} / \mathrm{h} / \mathrm{m}^{2}$, respectively, whilst NF of the acid whey presented a Javer of $18.5 \mathrm{~L} / \mathrm{h} / \mathrm{m}^{2}$ and of sugar bread as low as $12.4 \mathrm{~L} / \mathrm{h} / \mathrm{m}^{2}$. According to Bouchoux [19], permeate fluxes close to $35 \mathrm{~L} / \mathrm{h} / \mathrm{m}^{2}$ are considered suitable for industrial applications. The authors also studied the NF of two different industrial effluents containing lactic acid using a DK nanofiltration membrane. Kang [20] utilized the NF45 membrane for lactic acid separation from a fermentation broth and the permeate flux reported was $20 \mathrm{~L} / \mathrm{h} / \mathrm{m}^{2}$ at 27 bar. Both DK and NF45 present similar properties to OS-15 used in this study.

\subsubsection{Rejection of Sugars, Lactic Acid and Metal Ions}

The rejection of lactic acid and the other fermentation impurities is crucial for an efficient separation process since the goal is to produce polymer-grade lactic acid. A suitable membrane 
will mainly reject the residual sugars and proteins but not lactic acid. The type of substrate and the molecular weight (MW) of the compounds could also highly affect their rejection of the membrane.

The MF permeate of the defined glucose solution contained a very small amount of residual glucose (1.2 g/L), $87.5 \mathrm{~g} / \mathrm{L}$ lactic acid, as well as residual proteins (expressed as total Kjeldahl nitrogen), phosphorus, and metal anions with $\mathrm{Na}^{+}$being the predominant one, since $\mathrm{NaOH}$ was utilized for $\mathrm{pH}$ adjustment. The rejection of every component is presented in Table 4. Glucose and lactic acid rejection was $18.5 \%$ and $12.5 \%$ respectively. The highest rejections were observed for phosphorus with a value of $89.5 \%$, followed by $\mathrm{Mg}^{2+}(82.8 \%)$ and $\mathrm{Ca}^{2+}(64.5 \%)$.

Acid whey contained $13.1 \mathrm{~g} / \mathrm{L}$ unconsumed sugars, mainly lactose $(8.9 \mathrm{~g} / \mathrm{L})$ and lower amounts of galactose $(4.2 \mathrm{~g} / \mathrm{L})$, whilst the lactic acid concentration in the medium was $33 \mathrm{~g} / \mathrm{L}$. As expected, lactose rejection was $82 \%$, while galactose rejection was similar to the one of glucose (16.7\%), leading to a total sugar rejection of $61.1 \%$. The corresponding value for lactic acid was approximately $10 \%$. As in the case of the defined glucose medium, rejections of phosphorus $(55.8 \%), \mathrm{Mg}^{2+}(75.4 \%)$ and $\mathrm{Ca}^{2+}(68.8 \%)$ were high.

Sugar rejection for crust bread reached apparently $100 \%$ since no sugars were detected in the NF permeate stream. Lactic acid rejection was higher in comparison to the other substrates with a value of $22.4 \%$. Rejections of more than $90 \%$ were achieved for phosphorus (98.8\%) and for $\mathrm{Mg}^{2+}$ and $\mathrm{Ca}^{2+}$ (98.9\% and $96.6 \%$, respectively).

Residual sugars from sugar bread were $22.7 \mathrm{~g} / \mathrm{L}$ and they were composed of glucose $(9.3 \mathrm{~g} / \mathrm{L})$, sucrose $(12.3 \mathrm{~g} / \mathrm{L})$ and fructose $(1.1 \mathrm{~g} / \mathrm{L})$. Sucrose rejection was $89.4 \%$, similar to galactose $(82.5 \%)$, whereas for glucose the rejection was $23.6 \%$, while no fructose was detected in the permeate stream. Lactic acid rejection was the lowest for all of the studied cases with a value of only $2.5 \%$. Rejections of phosphorus, $\mathrm{Mg}^{2+}$ and $\mathrm{Ca}^{2+}$ were at comparable rates to the previously studied substrates $(67.1 \%$, $75.2 \%$ and $61.7 \%$ ).

The sugar rejection from the membrane was directly correlated to the concentrations in the fermentation broth. Goulas [21] studied the effect of different pressures during nanofiltration of a model sugar solution at $25^{\circ} \mathrm{C}$. Their experiments showed that increasing the pressure to 30 bar led to higher sugar rejections and to an increased permeate flux. Sugars are neutral molecules, which means that they are transferred through the NF membranes via convection and diffusion and their rejection is a result of size exclusion [18,22]. According to the study of Pontalier [23], the concentration of sugars in the feed affects their diffusive transport, regardless of the pressure employed. The variations of sugar rejections between the different fermentation broths can be attributed to the different size (monosaccharides versus disaccharides), their concentration in the medium, as well as the nature of other solutes since they can affect the properties of the membrane [18]. As a result, the disaccharides (maltose, sucrose, lactose) were rejected at high rates due to their higher molecular weight ( $\mathrm{MW}=342.3 \mathrm{~g} / \mathrm{mol}$ ).

Lactic acid rejection is highly affected by the feed composition. The lowest lactic acid rejection $(2.5 \%)$ was observed for sugar bread, whereas the highest rejection was monitored for crust bread $(22.4 \%)$. Even though the composition of the two substrates was quite similar, crust bread hydrolysate contained residual starch (approximately $30 \mathrm{~g} / \mathrm{L}$ ), which led to cake formation on the membrane. Interestingly, the lactic acid rejection in the defined medium was equal to $12.5 \%$, which could be mainly attributed to its high initial concentration $(87.5 \mathrm{~g} / \mathrm{L})$. In any case, lactic acid losses were relatively low and the retentate could be recycled in order to exploit the residual nutrients and recover the remaining lactic acid [8]. These values are in accordance with the cited publications. Bouchoux [19] also reported lactic acid rejections equal to 15 and $18 \%$. Since the $\mathrm{pH}$ was around 6.5 for all the fermentation broths, lactic acid was found mainly in its dissociated form, meaning that its rejection from the membrane was due to size exclusion and electrostatic interactions [19]. Li [24] studied the lactic acid recovery from acid whey fermentation using the nanofiltration membranes DS-5DK and DS-5HL. After setting the $\mathrm{pH}$ of the fermentation broth at 3.3, lactose retention was more than $90 \%$ for the case of DS-5DK but lactic acid recovery was only $76.9 \%$ and $50 \%$ for DS-5HL. The authors also found that lactic acid concentration in the broth greatly affects lactose retention from the membranes. Sikder [25] tested 
the NF3 membrane for the purification of lactic acid produced after fermentation of sugar cane juice. The authors reported the retention of $94 \%$ of unconsumed sugars but only $32 \%$ of lactic acid was recovered in the permeate stream; with a flux of $113 \mathrm{~L} / \mathrm{m}^{2} / \mathrm{h}$.

Besides sugar rejection, the separation of high molecular weight compounds (e.g., proteins) and metal ions is also crucial, since these compounds could decrease the purity of the final product. All of these compounds were present in different concentrations and they had a different molecular size and charge, meaning that the separation mechanisms involved were also different and quite complex. Protein rejection, expressed as total Kjeldahl nitrogen, was significant in all the studied cases. Acid whey contained the highest initial nitrogen content $(2368 \mathrm{mg} / \mathrm{L})$ and rejection in the permeate stream was equal to $40 \%$. The highest rejection of total nitrogen was achieved with crust bread $(77.5 \%)$, followed by sugar bread $(59.7 \%)$. Efficient separation of phosphorus was also carried out as rejections were more than $50 \%$ for all the substrates (Table 4 ), reaching $89.5 \%$ and $98.8 \%$ for the defined medium and crust bread respectively. The rejection of ions was equally high (Table 4). Sulphate and magnesium ions presented rejections higher than $70 \%$ for all the substrates. In such complex media, the main mechanism of rejection should be a size effect but electrostatic effects should play a role especially for the rejection of sulphate ions [19]. On top of that, sulphate ions have the same size as lactate, so rejections that high should definitely be correlated to charge repulsion effects [26]. Calcium rejections were more than $60 \%$ for the defined medium, acid whey, and sugar bread, whereas for crust bread it reached a value of $96.6 \%$ (Table 4). Calcium and magnesium rejections of 70 and $60 \%$ were previously reported in the literature [19]. Size exclusion should be again the main phenomena involved, even though it has been demonstrated that divalent ions can also interact with the surface on NF membranes, forming complexes [27]. High rejections of sulphate ions were also demonstrated in the study of Mänttäri [28], using the membrane Desal-5 DK for the purification of organic acids via nanofiltration from black liquor. Finally, chloride rejections were the lowest among the studied ions (Table 4). Chloride ions have a lower size and molecular weight to e.g., lactate and phosphate ions, and they could be transferred through the membrane more freely [19].

Table 5 presents the concentrations of lactic acid and the residual impurities of the permeate stream. Nanofiltration was highly efficient in removing residual proteins, phosphorus and metal ions, leading to an increase in the lactic acid purity from 3 to $13 \%$, depending on the substrate. The utilization of commercial nutrient sources led to the highest product purity $(77.6 \%)$. The starch-based substrates resulted in similar lactic acid purities to the defined medium, after nanofiltration. Acid whey was the least promising substrate since neither the final lactic acid fermentation yield $(0.6 \mathrm{~g} / \mathrm{g})$ nor the purity after filtration $(44.2 \%)$ were as high as the other studied media. The nanofiltered media could be further subjected to e.g., bipolar electrodialysis membranes and ion exchange chromatography for achieving polymer-grade purity values. 
Table 4. Rejections ( $\mathrm{R} \%$ ) of lactic acid, sugars and other nutrients present in the studied substrates after nanofiltration.

\begin{tabular}{cccccccccccccc}
\hline Substrate & Total Sugars & Glucose & Disaccharide & Fructose/Galactose & Lactic Acid & Total N & Total P $^{\mathbf{C l}^{-}}$ & $\mathbf{S O}_{4}^{2-}$ & $\mathbf{N a}^{+}$ & $\mathbf{K}^{+}$ & $\mathbf{M g}^{2+}$ & $\mathbf{C a}^{2+}$ \\
\hline $\begin{array}{c}\text { Defined } \\
\text { medium }\end{array}$ & 18.5 & 18.5 & - & - & 12.5 & 51.0 & 89.5 & 25.6 & 84 & 24.0 & 21.7 & 82.8 & 64.5 \\
Acid whey & 61.1 & - & 82.0 & 16.7 & 10.0 & 39.9 & 55.8 & 1.8 & 88.4 & 13.5 & 14.2 & 75.4 & 68.8 \\
Sugar bread & 63.0 & 23.6 & 89.4 & 100.0 & 2.5 & 59.7 & 67.1 & 6.1 & 71.4 & 24.9 & 25.2 & 75.2 & 61.7 \\
Crust bread & 100.0 & - & 100.0 & - & 22.4 & 77.5 & 98.8 & 1.2 & 68.8 & 16.6 & 26.5 & 98.9 & 96.6 \\
\hline
\end{tabular}

Table 5. Final concentrations (g/L) of lactic acid and fermentation impurities after nanofiltration and lactic acid purity (\%), before and after nanofiltration.

\begin{tabular}{|c|c|c|c|c|c|c|c|c|c|c|c|c|}
\hline Substrate & Total Sugars & Lactic Acid & Total N & Total P & $\mathrm{Cl}^{-}$ & $\mathrm{SO}_{4}{ }^{2-}$ & $\mathrm{Na}^{+}$ & $\mathrm{K}^{+}$ & $\mathrm{Mg}^{2+}$ & $\mathrm{Ca}^{2+}$ & LA Purity before NF & LA Purity after NF \\
\hline $\begin{array}{l}\text { Defined } \\
\text { medium }\end{array}$ & 1.0 & 76.6 & 0.4 & 0.1 & 0.03 & 0.02 & 20.2 & 0.3 & 0.004 & 0.02 & 74.9 & 77.6 \\
\hline Acid whey & 5.1 & 29.7 & 1.4 & 3.7 & 9.3 & 0.1 & 14.0 & 7.0 & 0.1 & 0.05 & 39.0 & 44.2 \\
\hline Sugar bread & 8.4 & 69.2 & 0.4 & 0.7 & 0.4 & 0.1 & 18.2 & 0.4 & 0.03 & 0.09 & 62.2 & 70.7 \\
\hline Crust bread & 0 & 52.2 & 0.3 & 0.01 & 1.4 & 0.03 & 14.5 & 0.3 & traces & traces & 68.7 & 75.9 \\
\hline
\end{tabular}




\section{Conclusions}

A defined medium with glucose, acid whey, sugar bread and crust bread hydrolysates were utilized as fermentation substrates for lactic acid production in pilot scales. The fermented media were then subjected to both microfiltration and nanofiltration in order to separate lactic acid from the majority of the other fermentation components. Microfiltration could efficiently separate the cell biomass and high molecular weight particles without major losses in lactic acid. High rejections of sugars, proteins and metal ions were achieved after nanofiltration, leading to a more than $10 \%$ improvement of lactic acid's purity in the alternative substrates. These results indicate that filtration could be industrially employed as the primary separation step of lactic acid even from complex fermentation broths.

Author Contributions: Data curation, M.A. and R.S.; Methodology, R.S.; Supervision, J.V.; Writing-original draft, M.A.; Writing-review \& editing, J.V.

Funding: Part of this research was funded by the EU program LIFE+, grant agreement LIFE10 ENV/ES/000479. The publication of this article was funded by the Open Access Fund of the Leibniz Association.

Conflicts of Interest: The authors declare no conflicts of interest.

\section{References}

1. Alves de Oliveira, R.; Komesu, A.; Vaz Rossell, C.E.; Maciel Filho, R. Challenges and opportunities in lactic acid bioprocess design-From economic to production aspects. Biochem. Eng. J. 2018, 133, $219-239$. [CrossRef]

2. E4tech. From the Sugar Platform to biofuels and biochemicals. Final Report for the European Commission Directorate-General Energy. Available online: https: / / ec.europa.eu/energy/sites/ener/files/documents/ EC\%20Sugar\%20Platform\%20final\%20report.pdf (accessed on 9 October 2018).

3. Demichelis, F.; Pleissner, D.; Fiore, S.; Mariano, S.; Michelle, I.; Gutiérrez, N.; Schneider, R.; Venus, J. Investigation of food waste valorization through sequential lactic acid fermentative production and anaerobic digestion of fermentation residues. Bioresour. Technol. 2017, 241, 508-516. [CrossRef] [PubMed]

4. Pleissner, D.; Demichelis, F.; Mariano, S.; Fiore, S.; Schneider, R.; Venus, J.; Michelle, I.; Guti, N. Direct Production of Lactic Acid Based on Simultaneous Saccharification and Fermentation of Mixed Restaurant Food Waste. 2017. Available online: https://www.sciencedirect.com/science/article/pii/ S0959652616321266 (accessed on 9 October 2018).

5. Kwan, T.H.; Vlysidis, A.; Wu, Z.; Hu, Y.; Koutinas, A.; Lin, C.S.K. Lactic acid fermentation modelling of Streptococcus thermophilus YI-B1 and Lactobacillus casei Shirota using food waste derived media. Biochem. Eng. J. 2017, 127, 97-109. [CrossRef]

6. Yang, X.; Zhu, M.; Huang, X.; Lin, C.S.K.; Wang, J.; Li, S. Valorisation of mixed bakery waste in non-sterilized fermentation for l-lactic acid production by an evolved Thermoanaerobacterium sp. strain. Bioresour. Technol. 2015, 198, 47-54. [CrossRef] [PubMed]

7. Pleissner, D.; Neu, A.K.; Mehlmann, K.; Schneider, R.; Puerta-Quintero, G.I.; Venus, J. Fermentative lactic acid production from coffee pulp hydrolysate using Bacillus coagulans at laboratory and pilot scales. Bioresour. Technol. 2016, 218, 167-173. [CrossRef] [PubMed]

8. Neu, A.K.; Pleissner, D.; Mehlmann, K.; Schneider, R.; Puerta-Quintero, G.I.; Venus, J. Fermentative utilization of coffee mucilage using Bacillus coagulans and investigation of down-stream processing of fermentation broth for optically pure 1(+)-lactic acid production. Bioresour. Technol. 2016, 211, 398-405. [CrossRef] [PubMed]

9. Pleissner, D.; Lau, Y.; Zhang, C.; Sze, C.; Lin, K. Plasticizer and Surfactant Formation from Food-Waste- and Algal Biomass-Derived Lipids. ChemSusChem 2015, 8, 1686-1691. [CrossRef] [PubMed]

10. Kuo, Y.C.; Yuan, S.F.; Wang, C.A.; Huang, Y.J.; Guo, G.L.; Hwang, W.S. Production of optically pure 1-lactic acid from lignocellulosic hydrolysate by using a newly isolated and d-lactate dehydrogenase gene-deficient Lactobacillus paracasei strain. Bioresour. Technol. 2015, 198, 651-657. [CrossRef] [PubMed]

11. Thuy, N.T.H.; Boontawan, A. Production of very-high purity succinic acid from fermentation broth using microfiltration and nanofiltration-assisted crystallization. J. Membr. Sci. 2017, 524, 470-481. [CrossRef] 
12. Davey, C.J.; Leak, D.; Patterson, D.A. Hybrid and mixed matrix membranes for separations from fermentations. Membranes 2016, 6, 17. [CrossRef] [PubMed]

13. Zaman, N.K.; Law, J.Y.; Chai, P.V.; Rohani, R.; Mohammad, A.W. Recovery of Organic Acids from Fermentation Broth Using Nanofiltration Technologies: A Review. J. Phys. Sci. 2017, 28, 85-109. [CrossRef]

14. Karp, S.G.; Igashiyama, A.H.; Siqueira, P.F.; Carvalho, J.C.; Vandenberghe, L.P.S.; Thomaz-Soccol, V.; Coral, J.; Tholozan, J.L.; Pandey, A.; Soccol, C.R. Application of the biorefinery concept to produce l-lactic acid from the soybean vinasse at laboratory and pilot scale. Bioresour. Technol. 2011, 102, 1765-1772. [CrossRef] [PubMed]

15. Lu, Z.; Wei, M.; Yu, L. Enhancement of pilot scale production of l(+)-lactic acid by fermentation coupled with separation using membrane bioreactor. Process Biochem. 2012, 47, 410-415. [CrossRef]

16. Fan, R.; Ebrahimi, M.; Czermak, P. Anaerobic membrane bioreactor for continuous lactic acid fermentation. Membranes 2017, 7, 26. [CrossRef] [PubMed]

17. Polom, E. The fouling of zirconium(IV) hydrous oxide-polyacrylate dynamically formed membranes during the nanofiltration of lactic acid solutions. Membranes 2013, 3, 415-423. [CrossRef] [PubMed]

18. Dey, P.; Linnanen, L.; Pal, P. Separation of lactic acid from fermentation broth by cross flow nanofiltration: Membrane characterization and transport modelling. Desalination 2012, 288, 47-57. [CrossRef]

19. Bouchoux, A.; Roux-de Balmann, H.; Lutin, F. Investigation of nanofiltration as a purification step for lactic acid production processes based on conventional and bipolar electrodialysis operations. Sep. Purif. Technol. 2006, 52, 266-273. [CrossRef]

20. Kang, S.H.; Chang, Y.K.; Chang, H.N. Recovery of ammonium lactate and removal of hardness from fermentation broth by nanofiltration. Biotechnol. Prog. 2004, 20, 764-770. [CrossRef] [PubMed]

21. Goulas, A.K.; Kapasakalidis, P.G.; Sinclair, H.R.; Rastall, R.A.; Grandison, A.S. Purification of oligosaccharides by nanofiltration. J. Membr. Sci. 2002, 209, 321-335. [CrossRef]

22. Tsuru, T.; Izumi, S.; Yoshioka, T.; Asaeda, M. Temperature effect on transport performance by inorganic nanofiltration membranes. AIChE J. 2000, 46, 565-574. [CrossRef]

23. Pontalier, P.; Ismail, A.; Ghoul, M. Mechanism for the selective rejection of solutes in nanofiltration membranes. Sep. Purif. Technol. 1997, 12, 175-181. [CrossRef]

24. Li, Y.; Shahbazi, A. Lactic Acid Recovery from Cheese Whey Fermentation Broth Using Combined Ultrafiltration and Nanofiltration Membranes. Appl. Biochem. Biotechnol. 2006, 129, 985-996. [CrossRef]

25. Sikder, J.; Chakraborty, S.; Pal, P.; Drioli, E.; Bhattacharjee, C. Purification of lactic acid from microfiltrate fermentation broth by cross-flow nanofiltration. Biochem. Eng. J. 2012, 69, 130-137. [CrossRef]

26. Peeters, J.M.M.; Boom, J.P.; Mulder, M.H.V.; Strathmann, H. Retention measurements of nanofiltration membranes with electrolyte solutions. J. Membr. Sci. 1998, 145, 199-209. [CrossRef]

27. Childress, A.E.; Elimelech, M. Effect of solution chemistry on the surface charge of polymeric reverse osmosis and nanofiltration membranes. J. Membr. Sci. 1996, 119, 253-268. [CrossRef]

28. Mänttäri, M.; Lahti, J.; Hatakka, H.; Louhi-Kultanen, M.; Kallioinen, M. Separation phenomena in UF and NF in the recovery of organic acids from kraft black liquor. J. Membr. Sci. 2015, 490, 84-91. [CrossRef]

(C) 2018 by the authors. Licensee MDPI, Basel, Switzerland. This article is an open access article distributed under the terms and conditions of the Creative Commons Attribution (CC BY) license (http://creativecommons.org/licenses/by/4.0/). 